\title{
Briefing: The ICE's Conservation Information Resource for Civil Engineers
}

Bill Addis MA (Cantab), PhD

Visiting Professor, Higher Technical School of Architecture, San Sebastian, spain (bill.addis@cantab.net)

The Conservation Information Resource for Civil Engineers (Circe) is a new resource available on the Institution of Civil Engineers' (ICE) website. It provides access to a wide range of information and guidance for civil and building engineers working on conservation, restoration and extension of the life of existing structures and is available to both members of the ICE and non-members. The paper summarises the reasons why Circe was developed and the needs it is intended to satisfy. It describes how the resource was developed and then describes its content. The paper concludes with thoughts about how the resource might be maintained and developed in the future.

\section{Introduction}

The Conservation Information Resource for Civil Engineers (Circe) is a new resource available on the Institution of Civil Engineers' (ICE) website (Circe, 2016). It provides a wide range of information and guidance for civil and building engineers working on conservation, restoration and extension of the life of existing structures (see Figure 1).

Circe gives users access to a wide variety of information that is available online. It does not contain any new, bespoke or original information.

Circe provides links to other websites, to documents that can be downloaded at no cost, to documents such as papers in learned journals that can be downloaded at a cost or at no cost for members of relevant organisations and to books and other publications that can be purchased or consulted in technical libraries.

Circe is available, by way of the ICE website, both to members of the ICE and to non-members.

Although a large proportion of work undertaken by civil and building engineers is on existing structures, the ICE website has hitherto focused largely on new construction. Circe was developed to broaden the scope of the ICE website to include work on existing structures.

Work on existing structures can take many forms, and many of the terms used to describe it have their origin in the work undertaken by architects on existing buildings - for example conservation, restoration, refurbishment, preservation, renovation, retrofit, remediation and rehabilitation. This range of work may also overlap with broader areas, such as work on ancient monuments and a range of heritage buildings and other structures, as well as archaeology and industrial archaeology. Such work is nowadays often seen as contributing to social, economic and environmental sustainability.

On the other hand, owners of existing structures, including bridges, canals, roads, railways, tunnels and harbours as well as buildings, are more often likely to think in terms of repair and maintenance and asset management.

In developing Circe, it was felt important to use a single general phrase to embrace what engineers and others would actually be doing, whether it is called repair, conservation or rehabilitation or any of the other terms often used.

The phrase chosen was 'extending the life of existing structures'. It was felt that this phrase can include the full range of work on existing structures, whether they be iconic or heritage structures or the far larger group of 'ordinary' existing structures such as road and rail bridges, canals and docks and their associated structures, and buildings ranging from 1930s' commercial buildings to 1960 s' residential buildings.

\section{The reasons for developing Circe}

While much of the engineering involved in working on existing structures is the same as that in working on new ones, a different approach is needed. Although having to respect many design and construction constraints, working on new structures usually includes significant freedom when drawing on a blank sheet of paper. When working on existing structures, however, the first activity has to be finding out as much as possible, or necessary, about the existing structure before any proposals can be made about extending its life. This activity may embrace historical and archival research as well as assessing the condition of the structure. It is also often essential to build an accurate picture of the history of previous repair, conservation and alteration works that might have been undertaken on the structure during its life. 


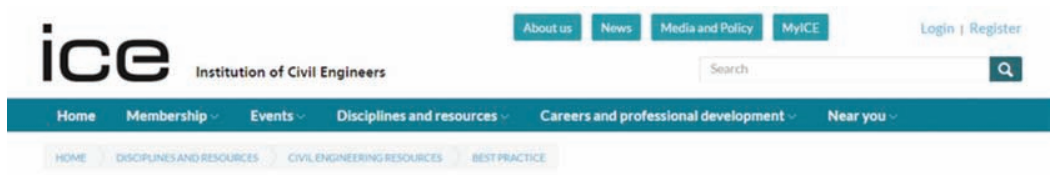

\section{The Conservation Information Resource for Civil Engineers}

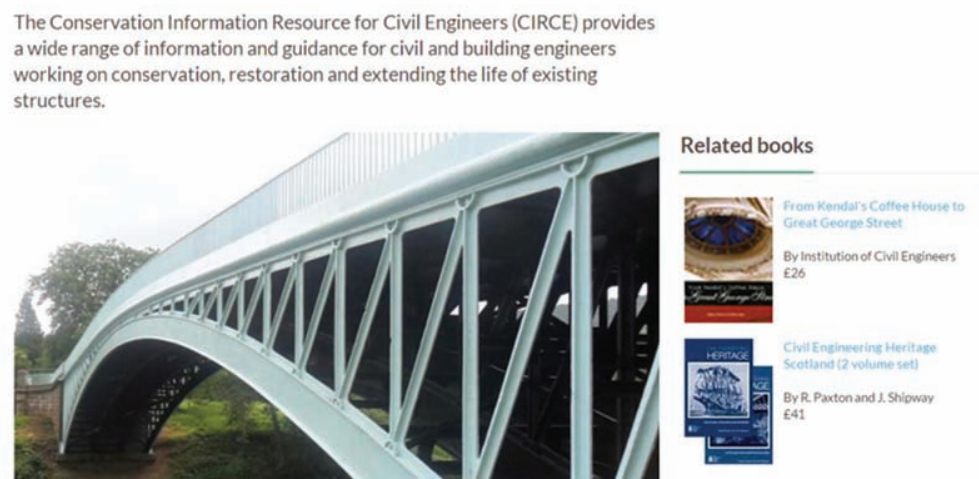

Figure 1. Screenshot of the Circe home page on the ICE website

Such work is generally not familiar to engineers who work only on new construction projects.

The main aim of Circe is to provide an information resource concerning work on existing structures to help those new or relatively new to the field. However, there are also some broader factors lying behind the need for such a resource.

- Few consulting engineers have formal education or attended short continuing professional development (CPD) courses addressing work on existing structures (architects are often better educated in this respect) (Addis, 2016).

- Many large clients (e.g. railways, highways, canals, heritage organisations) no longer employ many of their own engineers to work on existing structures. Rather, they nowadays rely on external consultants and contractors with wide-ranging experiences, but who will probably lack specific knowledge built up during long-term experience on the clients' particular types of existing structures.

- Specialists with robust experience of working on existing structures are often employed in very small firms, which are unable to bid for the very large contracts that are now common.

- Most large projects require very large firms of consulting engineers and contractors to bid for work on existing structures without necessarily having staff with relevant experience, hoping they can fill any gaps by employing small specialist firms.

Circe aims to provide a succinct, structured source of information to help non-specialists understand the issues that need to be addressed when working on existing structures. Hopefully, this might avoid some of the mistakes that have been made in the past when non-specialists have worked on existing structures.

\section{Developing the structure and scope of Circe}

The research undertaken to find and distil the information needed to create the website was funded by the ICE Research and Development Enabling Fund (ICE, 2016). Fundamental to the project proposal was a process of consultation with a group of advisors familiar with the contribution made by consulting engineers to work on existing structures. Those consulted included people with a wide range of experiences in relevant professional activities such as

- consulting engineers familiar with working on existing structures

- heritage organisations

members of major client organisations, including road, rail and waterway infrastructure and bridges

- academics undertaking research and delivering courses related to extending the life of existing structures

- authors of guidance documents for engineers

- designers of websites, in general, and those familiar with the ICE website, in particular

- providers of information for engineers (including the ICE Library)

- persons familiar with engineering conservation activities in many countries, including the UK, Ireland, Belgium, Spain, Germany, Italy, Austria and Switzerland.

During initial consultations, some potential users felt that a dedicated website would not have significant advantages, since any site on the Web can nowadays be found by using Internet search engines. The majority of consultees, however, felt that some editorial influence would be advantageous by way of preselecting and structuring the information resources.

It was generally agreed that a website hosted by the ICE should not attempt or claim to be comprehensive or authoritative, 
Engineering History and Heritage

Volume 169 Issue EH4
Briefing: The ICE's Conservation

Information Resource for Civil Engineers

Addis
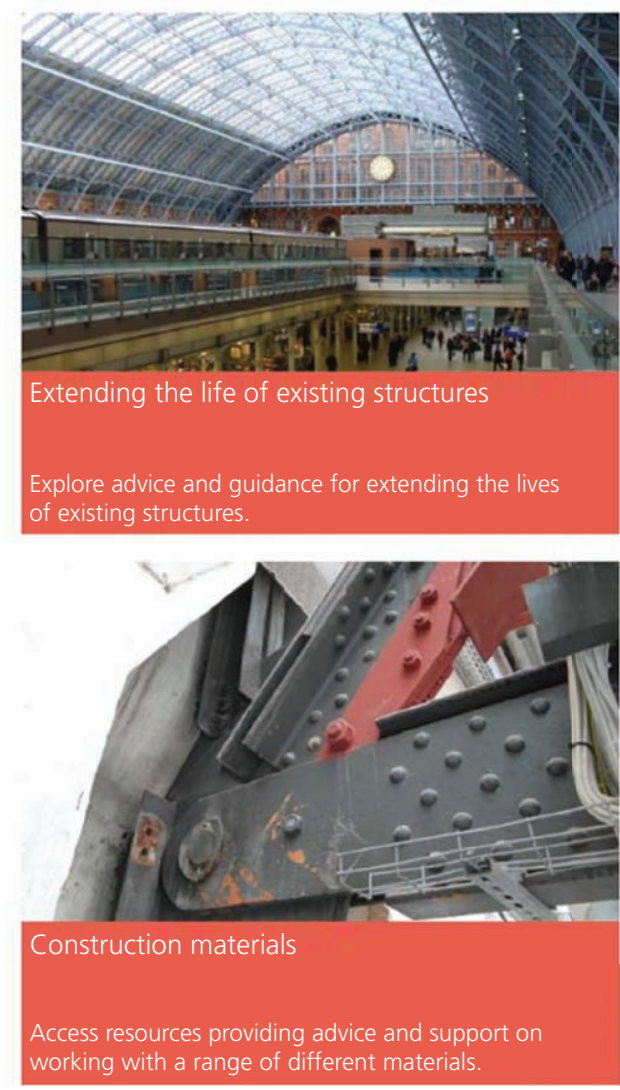
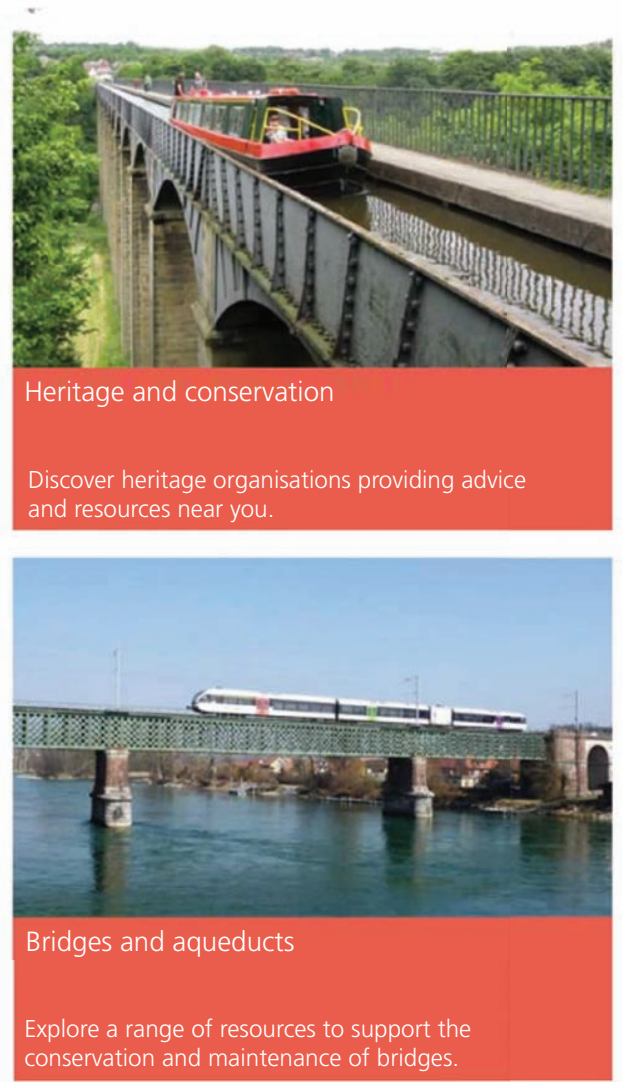

Figure 2. Screenshot showing access to some of the main categories within Circe

since that is not the role of the ICE. Rather, it should provide an introductory, almost pedagogic resource in the manner of the best-practice guidance and case study material already provided. It was also agreed that to serve this function, it would not be necessary to write any original material; rather, the Circe website should provide links to original materials generated by others who are experts in their fields. These materials should be in the form of websites or documents that can be downloaded from websites or links to printed materials available from conventional and online libraries. It was also recommended that users should be made aware, before following a link, of the level of detail that it may offer and whether the content would be instantly available (by way of downloading) or whether the link would lead to a bibliographical reference that would require the user to obtain the original from a library or by purchasing it. It was concluded that the level of detail could be well indicated simply by giving the number of pages in the source referred to. It was agreed that the immediate availability of a document would be best indicated by an easily visible icon: the icon DIRECT was finally chosen.

The advisors were consulted at several stages, and later versions were revised to reflect comments made on earlier ones. First, an early draft of the overall structure and the information to be provided in one section of the database was distributed for comment. This was followed by a full draft of the information for the first four sections that would be included in the pilot version of the website itself. A small pilot of the website was developed with the group Web manager of the ICE to achieve an appropriate on-screen appearance with easy linking between different pages of the website. This was developed into a fully working version of about two thirds of the anticipated content of Circe and launched as a working prototype in June 2016. The final version of Circe with its full range of contents was launched in October 2016, incorporating changes suggested by feedback on the pilot version. This version will be updated in 2017 to deal with dead links, new materials and the correction of errors.

\section{The structure and scope of Circe}

Circe provides a wide range of information and guidance for civil and building engineers working on conservation, restoration and extension of the life of existing structures.

Working on existing structures requires a methodology and approach that is different from those used when designing and constructing new ones. It is, first of all, essential to understand the current state of a structure before proposing interventions, stabilisation, remediation or strengthening. Circe is based on the 


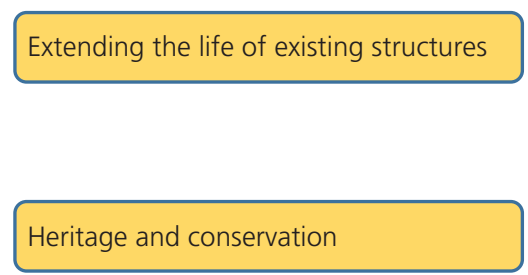

$$
\text { Construction materials }
$$$$
\text { Bridges and aqueducts }
$$

- Methodology and approaches

- Sources of information and guidance

- Registers

- Terminology

- International organisations

- National organisations: UK

- National organisations: Europe

- National organisations: rest of the world

- All materials

- Masonry - stone and brick

- Iron and steel

- Concrete and reinforced concrete

- Timber

- Miscellaneous materials

- All bridges

- Masonry bridges

- Iron and steel bridges

- Reinforced-concrete bridges

- Timber bridges

- Suspension and cable-stayed bridges

- Highway bridges

- Rail bridges

- Aqueducts

All buildings

- Masonry buildings

- Iron and steel frame buildings

- Concrete and reinforced-concrete buildings

- Timber frame buildings

Other building types

\section{Other structures}

- Canals

- Roads and highways

- Tunnels and sewers

- Dams and maritime structures

- Masts, towers and chimneys

Figure 3. The hierarchical structure of Circe

premise that good conservation and refurbishment of existing structures can be achieved only when those working on such projects understand as much as can be reasonably ascertained about

- the design and construction of the original structure

- the subsequent history of modifications, repairs and previous conservation and refurbishment works

- the current state of the existing structure and the materials of which it is made.
Based on this knowledge, good conservation and refurbishment of existing structures can be undertaken by applying appropriate repair, remediation, strengthening and protection techniques.

The information accessible by way of Circe is presented in a hierarchical way. The home page gives access to three categories of second-level pages (see Figure 2)

- introductory and background material concerning the methodologies and approaches that underlie work on existing 
Engineering History and Heritage

Volume 169 Issue EH4
Briefing: The ICE's Conservation

Information Resource for Civil Engineers

Addis structures and an overview of the many heritage organisations that may influence any work undertaken on existing structures

- information and guidance relating to assessing and remediating the most common construction materials that are likely to be encountered in an existing structure (masonry, concrete, iron, steel etc.)

- information and guidance relating to assessing and extending the life of various types of existing structures, including bridges, buildings, roads, canals and sewers.

Each of these main categories is further divided, generally by using a set of consistent subheadings (see Figure 3).

\subsection{Circe: extending the life of existing structures}

This section of the website provides guidance on the methodologies and approaches that need to be taken when engineers, and others, are working on existing structures (see Figure 4). This begins with general guidance on conservation from organisations including Historic Scotland, the Building Research Establishment, the Institution of Structural Engineers (e.g. Miller, 2015) and the International Committee for the Conservation of the Industrial Heritage.

Further sections deal with identifying existing structures and researching their history, as well as recording and surveying them.

Extending the life of existing structures

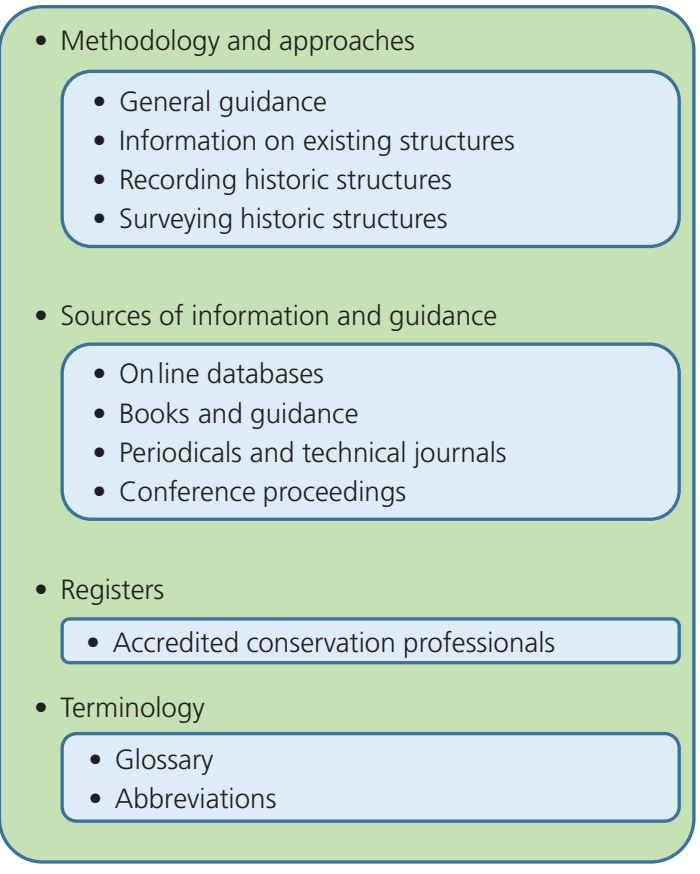

Figure 4. Structure of information in Circe under the main category 'Extending the life of existing structures'
The next section provides links to a variety of databases, publications and regular conferences that deal with extending the life of existing structures.

There follow several links to a number of accreditation schemes that have been developed by construction professionals in the UK for those of their members who have gained significant experience and expertise in working on existing structures. These include the Conservation Accreditation Register for Engineers (Care) (Avent and Addis, 2014; Care, 2016).

Finally, in this section, there are links to common abbreviations and a glossary of the many terms used in conservation and rehabilitation of existing structures.

\subsection{Circe: heritage and conservation}

Although Circe is intended for those working on any type of existing structure, there is naturally a certain bias towards those structures that are somehow worth retaining, whether this be entirely for economic reasons or somehow linked to the heritage value of a certain structure. There is no clear dividing line between these two categories.

For more than a century, conservation of built heritage has been promoted mainly by those concerned with architecture and the urban environment. Although engineers have usually been involved, in particular for major works, the engineering profession has only recently begun to take a greater interest. This has been due, to some extent, to a growing appreciation of engineering heritage structures, such as bridges or remains of industrial heritage, such as canals and harbours, which have generally not attracted the enthusiasm of architects.

This section of Circe provides an introduction to the many organisations that deal with built heritage, ranging in size from the UN Educational, Scientific and Cultural Organization (Unesco) to local interest groups in small villages. These organisations deal with heritage and conservation issues which are likely to arise when civil and building engineers work on conservation, restoration and extension of the life of existing structures (see Figure 5).

The links take the user of Circe to the websites of international heritage organisations and national heritage organisations in the UK, other European countries and the rest of the world. It is intended that this section will grow in the future, in particular to reflect the regular civil engineering heritage country profiles that have been published in this journal since the beginning of 2016 (e.g. Bühler, 2016; Crespo et al., 2016; Isohata, 2016; Jones and Thomas, 2016; Masterson, 2016).

\subsection{Circe: construction materials}

All engineers spend most of their time working with construction materials, whether the project is a bridge, a tunnel or a canal; however, those materials have been used to create an engineering structure. This section of Circe provides guidance on all types of 
Briefing: The ICE's Conservation

Information Resource for Civil Engineers

Addis
Heritage and conservation

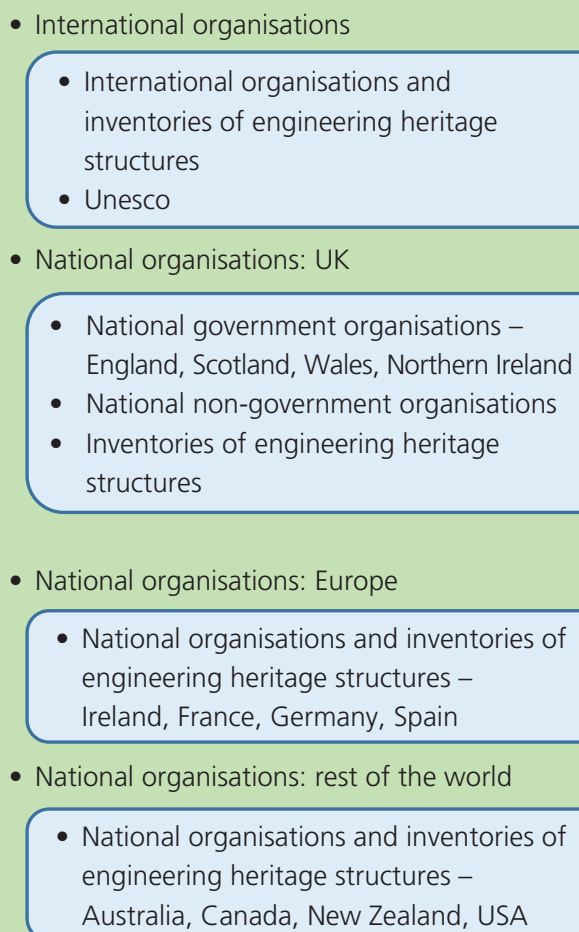

- National organisations: UK

- National government organisations England, Scotland, Wales, Northern Ireland

- National non-government organisations

- Inventories of engineering heritage structures

- National organisations: Europe

- National organisations and inventories of engineering heritage structures Ireland, France, Germany, Spain

- National organisations: rest of the world

- National organisations and inventories of engineering heritage structures Australia, Canada, New Zealand, USA

Figure 5. Structure of information in Circe under the main category 'Heritage and conservation'

construction materials that civil and building engineers are likely to encounter when working on conservation, restoration and extension of the life of existing structures (see Figure 6).

Each subcategory for each of the main materials provides links to information and guidance about the characteristics and properties of the materials; to methods and approaches for inspecting, assessing and appraising materials; and, finally, to techniques of and approaches to remediation, repair and conservation. The links to information for all materials are grouped under the same main headings - 'Characteristics and properties'; 'Inspection, assessment and appraisal'; and 'Remediation, repair and conservation'.

\subsection{Circe: bridges and aqueducts}

The remaining sections of Circe deal with various types of engineering structure, beginning with bridges and aqueducts. The links to information are grouped under four main headings: 'General guidance'; 'Inspection, assessment and appraisal'; 'Remediation, repair and conservation'; and 'Case studies' (see Figure 7).

After some information relevant to any type of bridge, four sections deal with bridges made of different materials, and four more deal with different types of bridges and aqueducts.

\section{Construction materials}

\section{- All materials}

- Characteristics and properties

- Inspection, assessment and appraisal

- Remediation, repair and conservation

- Masonry - stone and brick

- Same as for 'All materials'

- Iron and steel

- Same as for 'All materials'

- Concrete and reinforced concrete

- Same as for 'All materials'

- Timber

- Same as for 'All materials'

- Miscellaneous materials

- Same as for 'All materials'

Figure 6. Structure of information in Circe under the main category 'Construction materials'

As with construction materials, the subheadings are the same for each section: 'General guidance'; 'Inspection, assessment and appraisal'; 'remediation, repair and conservation'; and 'Case studies'.

\subsection{Circe: buildings}

The range and quality of information regarding conservation of existing buildings is generally more advanced than for other engineering structures because this information has been developed already over many decades and has responded to the centuries-old, architect-led concern for conserving and restoring existing buildings. The information is grouped according to the main structural material, which generally also defines the structural form (see Figure 8).

\subsection{Circe: other structures}

The final section of Circe embraces the remaining types of engineering structures not covered by previous sections (see Figure 9). Unlike buildings, structures included in this section are hardly ever embraced by architects and only with the growing interest in industrial archaeology and industrial heritage is their cultural importance becoming better recognised.

\section{Circe: the future}

The future of Circe will depend very much on how much it is used and by whom. The website includes a means of submitting feedback, and it is hoped that this will help the ICE to continue to 
Engineering History and Heritage

Volume 169 Issue EH4
Briefing: The ICE's Conservation

Information Resource for Civil Engineers

Addis

\section{Bridges and aqueducts}

\section{- All bridges}

- General guidance

- Inspection, assessment and appraisal

- Remediation, repair and conservation

- Case studies

- Masonry - stone and brick bridges

- Same as for 'All bridges'

- Iron and steel bridges

- Same as for 'All bridges'

- Concrete and reinforced-concrete bridges

- Same as for 'All bridges'

- Timber bridges

- Same as for 'All bridges'

- Suspension and cable-stayed bridges

- Same as for 'All bridges'

- Highway bridges

- Same as for 'All bridges'

- Rail bridges

- Same as for 'All bridges'

- Aqueducts

- Same as for 'All bridges'

Figure 7. Structure of information in Circe under the main category 'Bridges and aqueducts'

provide a resource that is of use to engineers, for members of the ICE and others.

However, it is not the intention that Circe will grow to infinity. It is intended that it remain succinct, out of respect to practising engineers, who are usually too busy to spend much time searching in vain. The idea is that Circe shall provide a rapid entry into the world of existing structures that will be augmented by years of practical experience.

The main aim is to ensure that the Circe website provides a succinct resource for practising engineers. It has a pedagogic function as well as a purely informative function. It is to be hoped that the coming decade or two will see engineers taking a more prominent role in the conservation of built heritage and appropriately extending the life of existing structure - whether they are of primary heritage interest or not.

\section{Buildings}

Figure 8. Structure of information in Circe under the main category 'Buildings'

It is hoped that Circe will help establish firm links between the ICE and various heritage and conservation organisations, such as Historic England and Historic Environment Scotland. Likewise, it is to be hoped that this resource may stimulate and be stimulated by a growing number of CPD courses for engineers.

It is also hoped that private firms will include a link to the Circe website on their own intranet so that it is instantly available to their staff.

A major issue to address will be to identify and develop a funding mechanism for the regular maintenance and updating that Circe will need. Discussions about these issues are already under way. While some have proposed that it be developed as a wiki site, growing and developing to reflect the users' interests and passions, others have expressed concern that an increased volume of materials will become progressively more difficult to use effectively and more costly to maintain, as has recently been found with the British Broadcasting Corporation cookery pages (Anon, 2016). The inevitable question of commercial sponsorship of Circe has not yet been explored.

\section{Conclusions}

Circe was developed to fill a perceived gap in the range of information available to engineers regarding work on existing structures, whether in the name of conservation, restoration, 
Briefing: The ICE's Conservation

Information Resource for Civil Engineers

Addis
Other structures

- General guidance
- Inspection, assessment and appraisal
- Remediation, repair and conservation
- Case studies

Figure 9. Structure of information in Circe under the main category 'Other structures'

refurbishment or other means of extension of the life of existing structures.

The resource was developed in consultation with a range of interested parties, and it is hoped that it will meet the needs of practising engineers - in particular those who are new or relatively new to working on existing structures.

It is hoped that the next 6 months or so will see a growing number of suggestions about how Circe might be improved. So far, the signs are good; reports of how useful Circe is have been matched by suggestions as to how it might be made more effective.

\section{Acknowledgements}

Circe has been developed with support from the ICE Research and Development Enabling Fund. The author is particularly indebted to the members of the advisory group who provided useful comments on the structure and scope of Circe during its development. Finally, the author is indebted to Steve Burleigh, the Group Web Manager of the ICE, who transformed the raw information into a user-friendly website, and also to Rob Curd, the Knowledge Content Manager of the ICE, who facilitated the development of the site and its public launch.

\section{REFERENCES}

Addis B (2016) Editorial. Proceedings of the Institution of Civil

Engineers - Engineering History and Heritage 169(3):

109-110, http://dx.doi.org/10.1680/jenhh.2016.169.3.109.
Anon (2016) BBC Food and Newsbeat websites to close under $£ 15 \mathrm{~m}$ savings plan. Daily Mail, 17 May. See http://www. dailymail.co.uk/wires/pa/article-3594233/BBC-bin-thousandsonline-recipes.html (accessed 16/09/2016).

Avent J and Addis W (2014) Editorial. Proceedings of the Institution of Civil Engineers - Engineering History and Heritage 167(3): 123-125, http://dx.doi.org/10.1680/ehah. 2014.167.3.123.

Bühler D (2016) Civil engineering heritage: country profile 2 Germany. Proceedings of the Institution of Civil Engineers Engineering History and Heritage 169(1): 46-50. http://dx. doi.org/10.1680/jenhh.15.0002.

Care (Conservation Accreditation Register for Engineers) (2016) http://www.careregister.org.uk/ (accessed 16/09/2016).

Circe (Conservation Information Resource for Civil Engineers) (2016) https://www.ice.org.uk/disciplines-and-resources/bestpractice/conservation-resources-for-civil-engineers (accessed 15/08/2016).

Crespo D, Fernández-Ordóñez D, Revuelta B and Clark M (2016) Civil engineering heritage: country profile 1 - Spain. Proceedings of the Institution of Civil Engineers Engineering History and Heritage 169(1): 42-45, http://dx. doi.org/10.1680/jenhh.15.00028.

ICE (Institution of Civil Engineers) (2016) Research and Development Enabling Fund. ICE, London, UK. See https:// www.ice.org.uk/about-us/what-we-do/research-anddevelopment-enabling-fund (accessed 15/08/2016).

Isohata I (2016) Civil engineering heritage: country profile Japan. Proceedings of the Institution of Civil Engineers Engineering History and Heritage 169(2): 95-100, http://dx. doi.org/10.1680/jenhh.16.00004.

Jones SK and Thomas K (2016) Civil engineering heritage: country profile - Wales, UK. Proceedings of the Institution of Civil Engineers - Engineering History and Heritage 169(2): 101-106, http://dx.doi.org/10.1680/jenhh.16.00005.

Masterson G (2016) Civil engineering heritage: country profile Scotland. Proceedings of the Institution of Civil Engineers Engineering History and Heritage 169(3): 140-146, http://dx. doi.org/10.1680/jenhh.16.00007.

Miller J (2015) Conservation compendium part 1: why keep it? engineers and the modern conservation movement. The Structural Engineer 93(1): 14-17.

\section{HOW CAN YOU CONTRIBUTE?}

To discuss this paper, please email up to 500 words to the editor at journals@ice.org.uk. Your contribution will be forwarded to the author(s) for a reply and, if considered appropriate by the editorial board, it will be published as discussion in a future issue of the journal.

Proceedings journals rely entirely on contributions from the civil engineering profession (and allied disciplines). Information about how to submit your paper online is available at www.icevirtuallibrary.com/page/authors, where you will also find detailed author guidelines. 